\title{
Remote preconditioning lessens the deterioration of pulmonary function after repeated coronary artery occlusion and reperfusion in sheep
}

\author{
Un préconditionnement éloigné diminue la détérioration de la fonction pul-
}

monaire après l'occlusion et la reperfusion répétées de l'artère coronaire

Zhengyuan Xia MD, Paul Herijgers MD PhD, Takahiro Nishida MD, Shigeyuki Ozaki MD PhD, Patrick Wouters MD PhD, Willem Flameng MD PhD

Purpose: We investigated whether remote organ preconditioning (RPC) can preserve pulmonary function following repeated myocardial ischemia/reperfusion in a model mimicking multi-vessel off-pump coronary artery bypass (OPCAB) revascularization.

Methods: Nine sheep (Group-RPC) underwent RPC by three episodes of five-minute occlusion and five-minute reperfusion of the iliac artery. Five sheep (Group-C) were time-matched controls. Afterwards, ten-minute occlusion and reperfusion of the left anterior descending, the first diagonal and the left circumflex coronary arteries were performed consecutively. Hemodynamic and respiratory parameters and arterial blood gases were measured until 120 min after the final coronary reperfusion. Anesthesia was maintained with halothane in oxygen and nitrous oxide. Animals were ventilated with a tidal volume of $15-20 \mathrm{~mL} \cdot \mathrm{kg}^{-1}$ in a non-rebreathing system, and a respiratory rate $14-16 \mathrm{~min}$, with $5-\mathrm{cm} \mathrm{H}_{2} \mathrm{O}$ positive end expiratory pressure after thoracotomy.

Results: Repeated coronary occlusion and reperfusion was associated in this experimental model with an increase in pulmonary vascular resistance (PVR) and pulmonary arterial pressure (PAP) and a decrease in $\mathrm{PaO}_{2}$ and $\mathrm{PaO}_{2} / \mathrm{FlO}_{2}$ in Group-C. After 120 min reperfusion, $\mathrm{PaO}_{2}$ and $\mathrm{PaO}_{2} / \mathrm{FIO}_{2}$ in Group-RPC were higher ( $192 \pm 69$ $\mathrm{mmHg}$ and $241 \pm 78 \mathrm{vs} \mid 15 \pm 54 \mathrm{mmHg}$ and $129 \pm 64, P<$ 0.05), while PVR and PAP were lower than in Group-C. At 120 min of reperfusion, $\mathrm{PaO}_{2}$ and $\mathrm{PaO}_{2} / \mathrm{FIO}_{2}$ were inversely correlated with PVR $(P<0.01)$.

Conclusions: RPC by transient occlusion of the iliac artery improves lung gas exchange after repeated coronary artery occlusion and reperfusion mimicking OPCAB surgery, and preserves low PVR in sheep.
Objectif : Nous avons vérifié si le préconditionnement éloigné d'un organe (PEO) peut préserver la fonction pulmonaire à la suite d'ischémie/reperfusion myocardique répétée chez un modèle imitant la revascularisation d'un pontage aortocoronarien plurivasculaire à cœur battant (PACCB)

Méthode : Neuf moutons (Groupe PEO) ont subi un PEO en trois épisodes d'occlusion de cinq minutes suivis de reperfusion de cinq minutes de l'artère iliaque. Cinq moutons (Groupe T) ont constitué le groupe témoin apparié dans le temps. Par la suite, nous avons réalisé successivement l'occlusion et la reperfusion, en dix minutes, des artères coronaires interventriculaire antérieure, première diagonale et circonflexe. Les paramètres hémodynamiques et respiratoires et la gazométrie du sang artériel ont été mesurés jusqu'à 120 min après la reperfusion coronaire finale. L'anesthésie a été maintenue avec de I'halothane dans un mélange d'oxygène et de protoxyde d'azote. Les animaux ont été ventilés selon un volume de $15-20 \mathrm{~mL} \cdot \mathrm{kg}^{-1}$ avec un système sans réinspiration, et une fréquence respiratoire de 14-16 min selon une pression positive en fin d'expiration de $5 \mathrm{~cm}$ de $\mathrm{H}_{2} \mathrm{O}$ après la thoracotomie.

Résultats : Dans ce modèle expérimental, l'occlusion et la reperfusion coronaires répétées ont été associées à une augmentation de la résistance vasculaire pulmonaire (RVP) et de la tension artérielle pulmonaire (TAP) ainsi qu'à une baisse de la $\mathrm{PaO}_{2}$ et de la $\mathrm{PaO}_{2} / \mathrm{FIO}_{2}$ dans le Groupe T. Dans le Groupe PEO, après 120 min de reperfusion, la $\mathrm{PaO}_{2}$ et la $\mathrm{PaO}_{2} / \mathrm{FIO}_{2}$ étaient plus élevées ( $192 \pm 69 \mathrm{mmHg}$ et 24 I \pm 78 vs $115 \pm 54 \mathrm{mmHg}$ et $129 \pm 64, P<0,05)$, tandis que la RVP et la TAP étaient plus faibles que dans le Groupe T. À 120 min de reperfusion, la $\mathrm{PaO}_{2}$ et la $\mathrm{PaO}_{2} / \mathrm{FIO}_{2}$ étaient en corrélation inverse avec la $\operatorname{RVP}(P<0,0$ l $)$.

From the Cardiovascular Research Unit, Center for Experimental Surgery and Anaesthesiology (C.E.H.A.), K.U.Leuven, Leuven, Belgium. Address correspondence to: Prof. Dr. Paul Herijgers, C.E.H.A., K.U.Leuven, Provisorium 1, Minderbroedersstraat 17, B-3000, Leuven, Belgium. Phone: +32-16-337298; Fax: +32-16-337855; E-mail: paul.herijgers@med.kuleuven.ac.be

This study was supported by a Research Grant from the Fund for Scientific Research - Flanders (Belgium; F.W.O.-Vlaanderen, KAN20011.5.057.01).

Accepted for publication October 22, 2002.

Revision accepted February 12, 2003. 
Conclusion : Le PEO par occlusion transitoire de l'artère iliaque améliore les échanges gazeux pulmonaires après l'occlusion et la reperfusion répétée de l'artère coronaire simulant un $P A C C B$ et il maintien une faible RVP.

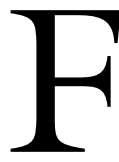

OLLOWING cardiac surgery, pulmonary dysfunction rate ranges from $<2 \%$ (adult respiratory distress syndrome) to $64 \%$ (postoperative atelectasis), ${ }^{1}$ and is one of the major contributors to postoperative morbidity and mortality. Off-pump coronary artery bypass (OPCAB) surgery may have the potential advantage of reducing postoperative pulmonary dysfunction compared with conventional coronary artery bypass grafting $(\mathrm{CABG})$ using extra-corporeal circulation. Manipulation of the heart during exposure of the obtuse marginal or the right $\mathrm{CABG}$ during OPCAB might, however, cause valvular regurgitation and jeopardize hemodynamics and pulmonary function. Also, patients with severe left ventricular dysfunction (ejection fraction $<30 \%$ ) will occasionally experience a rise in pulmonary arterial pressure (PAP) during $\mathrm{OPCAB}^{2}$ due to further ischemic deterioration of the ventricle. The rise in pulmonary artery pressure is followed by a drop in systolic pressure and a significant decrease in myocardial contractility, ${ }^{2}$ compromising the safe completion of the procedures without cardiopulmonary bypass (CPB). Respiratory insufficiency accounts for one tenth $(4 / 39)$ of the causes of early postoperative death in 2,052 patients receiving OPCAB surgery as reported by Tasdemir et $a l^{3} \mathrm{~A}$ transesophageal echocardiographic study showed that a five-minute coronary occlusion was associated with significantly elevated left ventricular wall motion score and concomitant significantly increased pulmonary artery pressure in patients undergoing OPCAB surgery. ${ }^{4}$ Other laboratory findings have shown that coronary artery occlusion caused pulmonary damage that was worsened by coronary reperfusion. ${ }^{5}$ All this suggests that although OPCAB surgery allows avoiding the deleterious pulmonary effects of $\mathrm{CPB}$, there still might be pulmonary dysfunction caused by the OPCAB procedure. ${ }^{6,7}$ Therefore, techniques to reduce pulmonary dysfunction may enhance the safety of coronary artery bypass surgery even when extracorporeal circulation is avoided.

It has been reported that brief ischemia of remote organs (remote preconditioning, RPC), such as mesentery $^{8}$ or gastrocnemius muscle, ${ }^{9}$ can reduce myocardial infarct size following prolonged ischemia and improve myocardial function. This RPC is much more attractive than the classical cardiac ischemic preconditioning since it avoids aortic cross clamping with its inherent risk of cerebral emboli. Moreover, in the case of beating heart OPCAB surgery, aortic cross clamping is, of course, impossible. It was shown recently that cardiac ischemic preconditioning protects pulmonary function in heart valve surgery. ${ }^{10}$ The effect of RPC on pulmonary function has not yet been fully explored. We postulated that RPC could improve lung gas exchange following myocardial ischemia/reperfusion. We tested this hypothesis using a clinically relevant animal model of OPCAB surgery in which RPC was achieved by three episodes of brief iliac artery occlusion and reperfusion, and myocardial ischemia and reperfusion was achieved by consecutive occlusion/reperfusion of three main coronary arteries.

\section{Methods \\ Animal preparation}

All animals received humane care in compliance with the European Convention on Animal Care. The animal Ethics Committee of the Katholieke Universiteit Leuven approved the study. Fourteen adult sheep weighing between $53-65 \mathrm{~kg}$ were used in this study. Nine sheep were pretreated by RPC, and, five control sheep were used. The sheep were fasted for $48 \mathrm{hr}$, but access to water was allowed until 20-24 hr before anesthesia.

\section{Anesthesia and surgical procedure}

The sheep were given im ketamine $15-20 \mathrm{mg} \cdot \mathrm{kg}^{-1}$. Anesthesia was induced with halothane (1-4 vol\%) in oxygen and maintained after endotracheal intubation with halothane (1.5-2.0 vol\%) in a mixture of oxygen and nitrous oxide. The animals were ventilated mechanically (Engström model 200, Engström, Sweden) at a respiratory rate of $14-16 \cdot \mathrm{min}^{-1}$, an in- to expiratory cycle ratio of $1: 2$, and the tidal volume (15-20 $\left.\mathrm{mL} \cdot \mathrm{kg}^{-1}\right)$ was individually adjusted to maintain arterial carbon dioxide tension $\left(\mathrm{PaCO}_{2}\right)$ between 35 to $45 \mathrm{mmHg}$. The tidal volume and respiratory rate for individual animals was not further adjusted during the experiment after baseline normal $\mathrm{PaCO}_{2}$ was achieved. Sigh breaths were given to treat increasing airway pressures. Angiocatheters (18 G and $20 \mathrm{G}$ ) were inserted respectively into a peripheral vein and a left ear artery for iv infusion and for arterial blood pressure monitoring and arterial blood sampling. A catheter was introduced into the right atrium through the jugular vein for continuous monitoring of central venous pressure. The electrocardiogram was monitored continuously. Fentanyl $(0.1 \mathrm{mg}$, Janssen, Beerse, Belgium) was given before surgery and was further 
administered in boluses during thoracotomy. Physiological saline was given intravenously at a constant rate of $6 \mathrm{~mL} \cdot \mathrm{kg}^{-1} \cdot \mathrm{min}^{-1}$ throughout the procedure. Heparin (400 IU $\left.\cdot \mathrm{kg}^{-1} i v\right)$ was administered before any vascular occlusion.

After a left thoracotomy was performed in the third intercostal space and the fourth rib was removed, a positive end-expiratory pressure of $5 \mathrm{~cm} \mathrm{H}_{2} \mathrm{O}$ was established. A 20-mm ultrasonic flow probe connected to a flow meter (Transonic System, Ithaca, NY, USA) was placed around the pulmonary artery for cardiac output (CO) measurement. Three fluid-filled pressure catheters were placed to measure left atrial, pulmonary artery, and aortic pressures. Suture snares were put respectively around the left anterior descending coronary artery distal to the first diagonal branch, the first diagonal branch itself and the left circumflex coronary artery. The left external iliac artery was exposed for RPC. All the hemodynamic variables were continuously recorded on a heat-writing recorder (Nihon-Kohden, Tokyo, Japan) after signal conditioning with a carrieramplifier (Triton Technology, San Diego, CA, USA). All signals were digitized on-line at $200 \mathrm{~Hz}$ with an analogue to digital converter equipped in the ConductPC hardware (CardioDynamics, Leiden, the Netherlands) and recorded on a computer. Blood gas variables were obtained from an automated blood gas analyzer (ABL3, Radiometer, Copenhagen, Denmark). The pulmonary vascular resistance (PVR) was calculated as: $\mathrm{PVR}=80 *(\mathrm{PAP}-\mathrm{LAP}) / \mathrm{CO}$ from PAP, left atrial pressure $(\mathrm{LAP})$ and $\mathrm{CO}$.

\section{Experimental protocol}

Fourteen sheep were randomly assigned by using sealed envelopes to a control group (Group-C, $n=5$ ) and a RPC group (Group-RPC, $n=9$ ). Blood gases, respiratory and basic hemodynamic variables were recorded after induction of anesthesia. During instrumentation, basic hemodynamic variables did not change, and baseline data were recorded ten minutes after completion of the surgical instrumentation. RPC was subsequently achieved by three episodes of fiveminute occlusion followed by five-minute reperfusion of the iliac artery, and data after preconditioning were recorded ten minutes after the final reperfusion of the iliac artery, or time-matched in Group-C which did not undergo iliac artery occlusion and reperfusion.

Subsequently, animals in both groups were subjected to repeated coronary occlusion and reperfusion. Firstly, the left anterior descending coronary artery was occluded for ten minutes. Ten minutes after left anterior descending coronary reperfusion, the first diagonal branch was occluded for ten minutes followed by reper- fusion, ten minutes afterwards, the circumflex was occluded for ten minutes and then reperfused. Arterial blood samples were taken, and hemodynamic and respiratory variables recorded every $30 \mathrm{~min}$ after circumflex reperfusion until $120 \mathrm{~min}$. Successful coronary occlusion was checked, by observing the immediate colour change of the tissues perfused by the corresponding arteries. Reperfusion was checked by the return of the bright red colour of the tissues. After the completion of the experiment, suture snares were checked to see if they completely circled coronary arteries, to ensure that occlusion of the corresponding coronary arteries was complete in each animal.

\section{Statistical analysis}

The significance of differences within the same group was determined by repeated measures ANOVA, with Dunnett's multiple comparison test and Tukey's multiple comparison test as appropriate. Statistical significance between the two groups was determined using unpaired Student's t test with Welch's correction. All data are presented as mean \pm standard deviation (SD) and $P<0.05$ was considered significant. Power calculations comparing the two groups were performed for the observed values obtained after 120 min of reperfusion (the final measurement) for the major outcomes concerning pulmonary function: this gives for PAP $B=0.83$, PVR $\beta=0.91$, PAP-LAP $\beta=0.92$, $\mathrm{PaO}_{2} ß=0.77, \mathrm{PaO}_{2} / \mathrm{FIO}_{2} ß=0.85$. The power calculations were performed using the online power calculators from the UCLA Department of Statistics (http://calculators.stat.ucla.edu/powercalc/).

\section{Results}

Animals in Group-RPC and Group-C did not differ significantly in body weight $(58.3 \pm 5.9 \mathrm{~kg}$ vs $60.0 \pm$ $3.4 \mathrm{~kg}$ ), anesthetic doses used, fractional inspired oxygen $\left(\mathrm{FIO}_{2}\right)$ and peak airway pressure throughout the procedure (Table I). As shown in Table II, hemodynamic variables were comparable in both groups at baseline. RPC immediately decreased the PVR. Mean PAP and PVR in Group-C increased gradually during reperfusion and after $120 \mathrm{~min}$ of reperfusion were higher than the corresponding baseline values. RPC prevented this increase in mean PAP and PVR. An increase of the transpulmonary pressure gradient, calculated as the pressure difference between the mean PAP and LAP, was observed in Group-C after reperfusion. This transpulmonary pressure gradient was higher in the control group than that in Group-RPC after 90 and $120 \mathrm{~min}$ of reperfusion. Repeated coronary occlusion and reperfusion was associated with a decrease in systemic arterial pressure and CO in both 
TABLE I Anesthetic gas and ventilatory variables

\begin{tabular}{|c|c|c|c|c|c|}
\hline & Baseline & Preconditioned & 30’ reperfusion & 90' reperfusion & 120' reperfusion \\
\hline \multicolumn{6}{|c|}{ Halothane (vol\%) } \\
\hline Group-RPC & $2.0 \pm 0.4$ & $1.9 \pm 0.4$ & $1.9 \pm 0.5$ & $1.9 \pm 0.5$ & $1.9 \pm 0.5$ \\
\hline Group-C & $1.8 \pm 0.3$ & $1.8 \pm 0.3$ & $1.8 \pm 0.3$ & $1.8 \pm 0.3$ & $1.8 \pm 0.3$ \\
\hline \multicolumn{6}{|l|}{$\mathrm{FIO}_{2}$} \\
\hline Group-RPC & $0.83 \pm 0.1$ & $0.82 \pm 0.1$ & $0.76 \pm 0.1$ & $0.79 \pm 0.1$ & $0.80 \pm 0.1$ \\
\hline Group-C & $0.83 \pm 0.1$ & $0.81 \pm 0.1$ & $0.87 \pm 0.1$ & $0.87 \pm 0.1$ & $0.88 \pm 0.1$ \\
\hline \multicolumn{6}{|c|}{ P-Paw $\left(\mathrm{cm} \mathrm{H}_{2} \mathrm{O}\right)$} \\
\hline Group-RPC & $22.2 \pm 9.3$ & $24.4 \pm 3.2$ & $26.4 \pm 4.4$ & $26.4 \pm 4.4$ & $27.2 \pm 4.1$ \\
\hline Group-C & $23.0 \pm 2.4$ & $23.8 \pm 2.5$ & $24.5 \pm 3.3$ & $24.5 \pm 3.3$ & $26.5 \pm 2.4$ \\
\hline
\end{tabular}

Values are means \pm standard deviations. No significant differences between the groups were observed. $\mathrm{FIO}_{2}=$ fractional inspired oxygen; P-Paw = peak airway pressure.

TABLE II Hemodynamic variables

\begin{tabular}{|c|c|c|c|c|c|}
\hline & Baseline & Preconditioned & 30' reperfusion & 90' reperfusion & 120' reperfusion \\
\hline \multicolumn{6}{|c|}{ HR (beats. $\min ^{-1}$ ) } \\
\hline Group-RPC & $97 \pm 21$ & $91 \pm 19$ & $92 \pm 19$ & $90 \pm 20$ & $87 \pm 20$ \\
\hline Group-C & $93 \pm 18$ & $92 \pm 16$ & $92 \pm 16$ & $96 \pm 19$ & $90 \pm 16$ \\
\hline \multicolumn{6}{|c|}{$\mathrm{MAP}(\mathrm{mmHg})$} \\
\hline Group-RPC & $77.3 \pm 8.6$ & $74.1 \pm 7.8$ & $56.8 \pm 10.7^{*}$ & $56.3 \pm 12.9^{*}$ & $53.2 \pm 9.8^{*} \dagger$ \\
\hline Group-C & $77.9 \pm 14.4$ & $81.1 \pm 16.0$ & $47.3 \pm 16.8^{*}$ & $51.9 \pm 13.7^{*}$ & $38.1 \pm 8.4^{*}$ \\
\hline \multicolumn{6}{|l|}{$\mathrm{PAP}(\mathrm{mmHg})$} \\
\hline Group-RPC & $23.9 \pm 6.3$ & $19.6 \pm 5.2$ & $21.3 \pm 5.5$ & $20.7 \pm 4.2$ & $20.4 \pm 4.2 \dagger$ \\
\hline Group-C & $23.2 \pm 4.1$ & $24.0 \pm 4.9$ & $23.2 \pm 4.6$ & $25.6 \pm 5.4$ & $27.6 \pm 4.6 \ddagger$ \\
\hline \multicolumn{6}{|l|}{$\mathrm{CO}\left(\mathrm{L} \cdot \mathrm{min}^{-1}\right)$} \\
\hline Group-RPC & $3.4 \pm 0.5$ & $3.5 \pm 0.5$ & $3.1 \pm 0.5$ & $2.9 \pm 0.5^{*}$ & $2.9 \pm 0.5 * \dagger$ \\
\hline Group-C & $3.7 \pm 0.5$ & $3.6 \pm 0.6$ & $2.5 \pm 0.5^{*}$ & $2.4 \pm 0.9^{*}$ & $2.2 \pm 0.4^{*}$ \\
\hline \multicolumn{6}{|c|}{ PVR (dynes $\cdot \sec ^{-1} \cdot \mathrm{cm}^{-5}$ ) } \\
\hline Group-RPC & $339 \pm 122$ & $227 \pm 108 \dagger \ddagger$ & $279 \pm 90 \dagger$ & $311 \pm 106 \dagger$ & $303 \pm 107 \dagger$ \\
\hline Group-C & $359 \pm 88$ & $387 \pm 87$ & $448 \pm 198$ & $703 \pm 435 \ddagger$ & $725 \pm 254 \ddagger$ \\
\hline \multicolumn{6}{|c|}{$\mathrm{LAP}(\mathrm{mmHg})$} \\
\hline Group-RPC & $9.7 \pm 2.8$ & $9.7 \pm 2.6$ & $10.4 \pm 2.8$ & $9.8 \pm 2.2$ & $9.9 \pm 2.3$ \\
\hline Group-C & $6.8 \pm 3.3$ & $7.0 \pm 3.4$ & $9.2 \pm 5.8$ & $8.4 \pm 5.1$ & $8.6 \pm 3.5$ \\
\hline \multicolumn{6}{|c|}{ PAP-LAP (mmHg) } \\
\hline Group-RPC & $14.2 \pm 5.3$ & $9.9 \pm 4.8 \dagger$ & $10.9 \pm 4.3$ & $10.9 \pm 3.5 \dagger$ & $10.6 \pm 3.3 \$$ \\
\hline Group-C & $16.3 \pm 3.2$ & $17.0 \pm 2.3$ & $14.0 \pm 6.0$ & $17.2 \pm 4.1$ & $19.0 \pm 4.8$ \\
\hline \multicolumn{6}{|c|}{ CVP $(\mathrm{mmHg})$} \\
\hline Group-RPC & $8.5 \pm 3.7$ & $8.5 \pm 3.6$ & $8.0 \pm 2.9$ & $8.3 \pm 2.6$ & $9.0 \pm 2.2$ \\
\hline Group-C & $7.0 \pm 2.8$ & $10.5 \pm 2.1$ & $11.0 \pm 2.8$ & $10.0 \pm 2.8$ & $11.0 \pm 4.2$ \\
\hline \multicolumn{6}{|l|}{$\mathrm{Hb}\left(\mathrm{g} \cdot \mathrm{dL}^{-1}\right)$} \\
\hline Group-RPC & $9.8 \pm 1.8$ & $9.9 \pm 1.9$ & $10.4 \pm 1.6$ & $10.3 \pm 1.7$ & $9.9 \pm 1.6$ \\
\hline Group-C & $9.8 \pm 0.9$ & $10.0 \pm 1.6$ & $10.7 \pm 1.1$ & $10.9 \pm 0.6$ & $11.2 \pm 2.1$ \\
\hline
\end{tabular}

Values are means \pm standard deviations. $\mathrm{HR}=$ heart rate $\mathrm{MAP}=$ mean arterial pressure $\mathrm{PAP}=$ mean pulmonary pressure $; \mathrm{CO}=$ cardiac output $\mathrm{PVR}=$ pulmonary vascular resistance; $\mathrm{LAP}=$ left atrium pressure; PAP-LAP $=$ difference between $\mathrm{PAP}$ and $\mathrm{LAP} ; \mathrm{CVP}=\mathrm{central}$ venous pressure; $\mathrm{Hb}=$ hemoglobin. ${ }^{*} P<0.01$ vs baseline, $\uparrow P<0.05$ vs Group- $\mathrm{C}, \ddagger P<0.05$ vs baseline, $\$ P<0.01$ vs Group-C.

Group-C and Group-RPC. After 120 min reperfusion, the mean systemic arterial pressure and $\mathrm{CO}$ was lower in Group C than in Group RPC. Heart rate, LAP and central venous pressure did not change significantly over time in either group.

$\mathrm{PaO}_{2}$ and $\mathrm{PaO}_{2} / \mathrm{FIO}_{2}$ in Group-C decreased progressively after reperfusion and were lower than the baseline values after $120 \mathrm{~min}$ of reperfusion (Table III). However, no significant changes of $\mathrm{PaO}_{2}$ and $\mathrm{PaO}_{2} / \mathrm{FIO}_{2}$ were observed in Group-RPC throughout the procedure. After 120 min of reperfusion, $\mathrm{PaO}_{2}$ and $\mathrm{PaO}_{2} / \mathrm{FIO}_{2}$ in Group-C were lower than that in Group-RPC $(P<0.05)$. Concomitantly, $\mathrm{PaCO}_{2}$ in Group-C increased after 90 min reperfusion and was higher than that in Group-RPC (Table III). In Group-RPC, $\mathrm{PaCO}_{2}$ and $\mathrm{pH}$ values remained within the normal range after reperfusion. 
TABLE III Arterial blood gases

\begin{tabular}{|c|c|c|c|c|c|}
\hline & Baseline & Preconditioned & 30' reperfusion & 90' reperfusion & 120' reperfusion \\
\hline \multicolumn{6}{|c|}{$\overline{\mathrm{PaO}_{2}(\mathrm{mmHg})}$} \\
\hline Group-RPC & $249 \pm 29$ & $236 \pm 51$ & $201 \pm 61$ & $190 \pm 73$ & $192 \pm 69^{*}$ \\
\hline Group-C & $225 \pm 84$ & $204 \pm 32$ & $157 \pm 83$ & $127 \pm 71$ & $115 \pm 54 \dagger$ \\
\hline \multicolumn{6}{|l|}{$\mathrm{PaO}_{2} / \mathrm{FIO}_{2}$} \\
\hline Group-RPC & $306 \pm 64$ & $294 \pm 70$ & $262 \pm 60$ & $237 \pm 74^{*}$ & $241 \pm 78^{*}$ \\
\hline Group-C & $269 \pm 98$ & $255 \pm 60$ & $182 \pm 94$ & $147 \pm 84$ & $129 \pm 64 \dagger$ \\
\hline \multicolumn{6}{|c|}{$\mathrm{PaCO}_{2}(\mathrm{mmHg})$} \\
\hline Group-RPC & $39.1 \pm 4.2$ & $41.8 \pm 4.1$ & $40.9 \pm 2.8$ & $40.5 \pm 3.9^{*}$ & $42.1 \pm 4.0$ \\
\hline Group-C & $37.5 \pm 3.2$ & $39.5 \pm 4.0$ & $41.8 \pm 4.2$ & $46.6 \pm 5.7 \dagger$ & $45.4 \pm 7.3 \dagger$ \\
\hline \multicolumn{6}{|l|}{$\mathrm{pH}$} \\
\hline Group-RPC & $7.42 \pm .04$ & $7.38 \pm .03$ & $7.38 \pm .04$ & $7.37 \pm .04$ & $7.36 \pm .04$ \\
\hline Group-C & $7.40 \pm .05$ & $7.35 \pm .08$ & $7.32 \pm .04$ & $7.31 \pm .06$ & $7.31 \pm .08$ \\
\hline \multicolumn{6}{|c|}{$\mathrm{HCO}_{3}\left(\mathrm{mmoL} \cdot \mathrm{L}^{-1}\right)$} \\
\hline Group-RPC & $25 \pm 3$ & $25 \pm 3$ & $24 \pm 2$ & $22 \pm 4$ & $23 \pm 2$ \\
\hline Group-C & $23 \pm 2$ & $22 \pm 4$ & $21 \pm 2$ & $22 \pm 2$ & $21 \pm 2$ \\
\hline
\end{tabular}

Values are means \pm standard deviations. ${ }^{*} P<0.05$ vs Group-C; $\dagger P<0.05$ vs baseline; $\mathrm{PaO}_{2}=$ arterial oxygen partial pressure; FIO ${ }_{2}=$ fractional inspired oxygen; $\mathrm{PaCO}_{2}=$ carbon dioxide partial pressure; $\mathrm{pH}=$ blood $\mathrm{pH}$ value; $\mathrm{HCO}_{3}=$ blood bicarbonate.
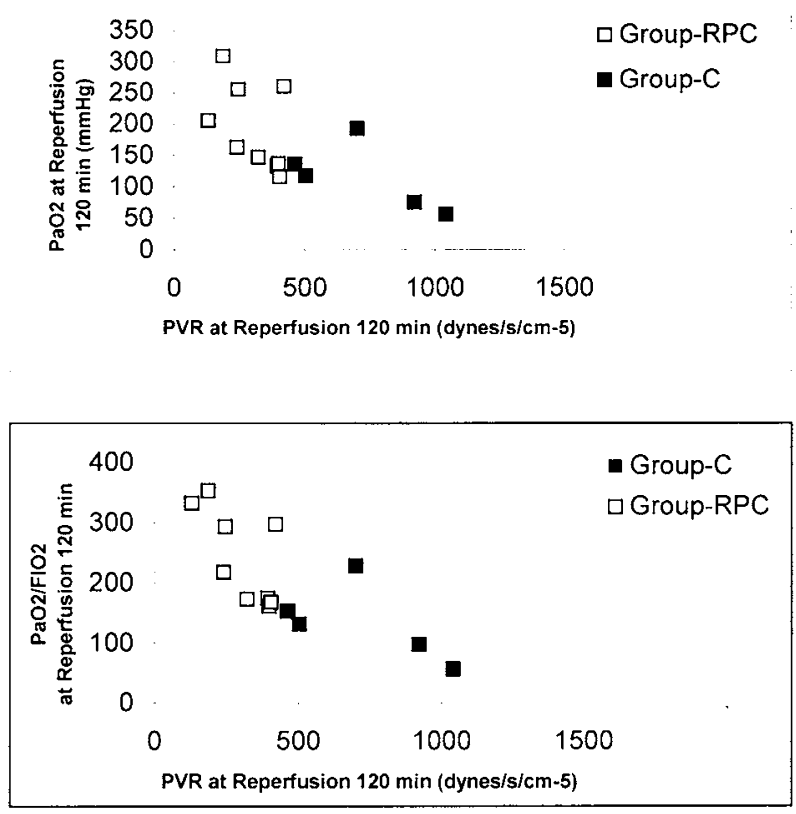

FIGURE 1 Correlation between pulmonary vascular resistance (PVR) and $\mathrm{PaO}_{2}$ and $\mathrm{PaO}_{2} / \mathrm{FIO}_{2}$ after 120 min reperfusion. After 120 min reperfusion, PVR negatively correlated with $\mathrm{PaO}_{2}(\mathrm{r}=-$ $0.6660, P=0.009$, top $)$ and with $\mathrm{PaO}_{2} / \mathrm{FIO}_{2}(\mathrm{r}=-0.7493, P=$ 0.002 , bottom).

Figure 1 depicts the negative correlation between PVR and $\mathrm{PaO}_{2}$ as well as $\mathrm{PaO}_{2} / \mathrm{FIO}_{2}$ after $120 \mathrm{~min}$ reperfusion $(P<0.01)$. As shown in Figure 2 , changes of PVR $30 \mathrm{~min}$ after reperfusion were correlated with impaired $\mathrm{PaO}_{2}$ and $\mathrm{PaO}_{2} / \mathrm{FIO}_{2}$ after 120 min of reperfusion.

\section{Discussion}

This experiment suggests that brief remote ischemic preconditioning prevents the increase in pulmonary artery pressures following consecutive multiple coronary arteries occlusion and reperfusion, a situation that mimics clinical OPCAB surgery. Our main findings are: (a) this experimental protocol with consecutive coronary occlusion-reperfusion increases PVR and jeopardizes lung gas exchange, which is evidenced by the reduced $\mathrm{PaO}_{2}$ and $\mathrm{PaO}_{2} / \mathrm{FIO}_{2}$ after reperfusion in the control group; (b) RPC reduces PVR and improves lung gas exchange after repeated coronary artery occlusion and reperfusion, and reduces PVR.

Postoperative pulmonary dysfunction, a potentially lethal syndrome, has been reported to occur after OPCAB surgery, ${ }^{2,4}$ vascular surgery ${ }^{11}$ and after $\mathrm{CPB} .{ }^{12,13} \mathrm{It}$ is associated with a significant decrease in $\mathrm{PaO}_{2}$ and $\mathrm{PaO}_{2} / \mathrm{FIO}_{2}$. OPCAB surgery implies one or more coronary arteries to undergo occlusion and reperfusion. During reperfusion, specific myocardial enzymes (presumably leaked from damaged or necrotic tissue) and inflammatory cytokines ${ }^{14}$ are being washed out and reach the lungs, ${ }^{15}$ which might lead to lung injury. A series of acute experimental studies ${ }^{5,16-18}$ has demonstrated that coronary artery occlusion and reperfusion resulted in pulmonary edema, evidenced by an increase in extra-vascular lung water. Increased pulmonary microvascular permeability is suggested as one of the possible mechanisms. Although the mediators of the rise in pulmonary per- 

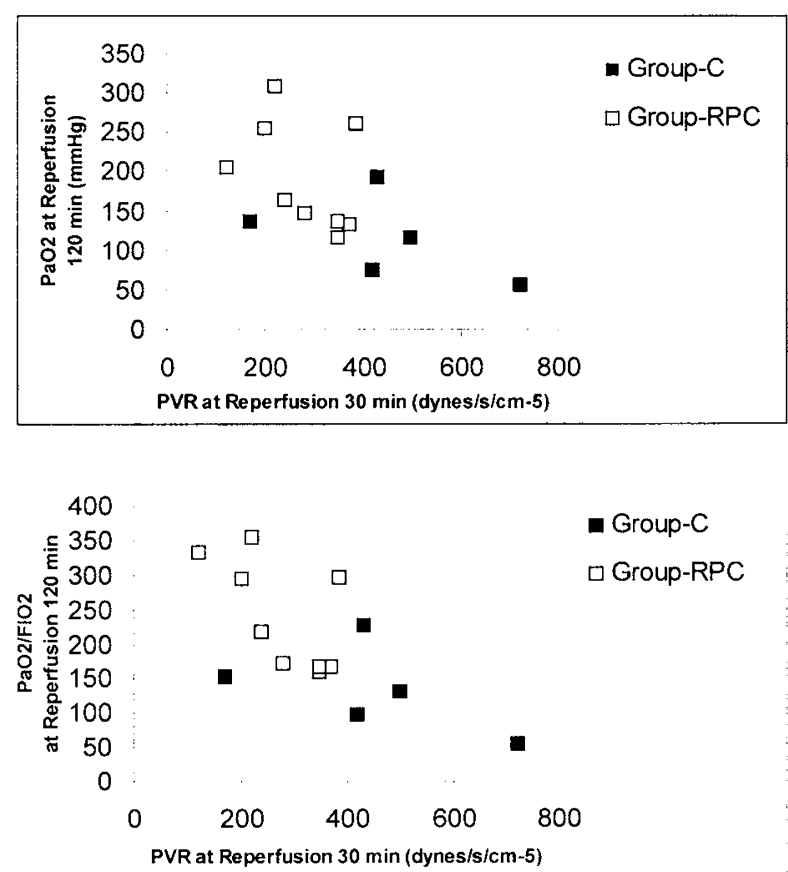

FIGURE 2 Pulmonary vascular resistance (PVR) after $30 \mathrm{~min}$ reperfusion predicted changes of $\mathrm{PaO}_{2}$ and $\mathrm{PaO}_{2} / \mathrm{FIO}_{2}$ after 120 min reperfusion. PVR after $30 \mathrm{~min}$ reperfusion negatively correlated with $\mathrm{PaO}_{2}(\mathrm{r}=-0.5712, P=0.03$, top $)$ and with $\mathrm{PaO}_{2} / \mathrm{FIO}_{2}(\mathrm{r}$ $=-0.6743, P=0.008$, bottom) after 120 min reperfusion.

meability have not been clearly identified, increasing evidence suggests that IL- $6, \quad$ IL- ${ }^{14}$ and prostaglandins ${ }^{19}$ are among the potential contributors. Infusing indomethacin ${ }^{19}$ reduced extra-vascular lung water after coronary artery occlusion in dogs. In a sheep model, Stamler et al..$^{20}$ and Friedman et al. ${ }^{21}$ showed that myocardial ischemia and reperfusion was associated with an increase in PVR, which was accompanied by an increase in plasma thromboxane. Inhibition of thromboxane synthesis eliminated the lung injury seen in this model. ${ }^{21}$ Extra-vascular lung water was not measured in our model. Given the increase of PAP and PVR in Group-C, combined with a continuous decrease of $\mathrm{PaO}_{2}$ and $\mathrm{PaO}_{2} / \mathrm{FIO}_{2}$ as well as an increase in $\mathrm{PaCO}_{2}$, pulmonary edema may be one of the major contributors to the deterioration of pulmonary function in our model.

Recently, Fehrenbach et al. ${ }^{19}$ reported that the extent of lung epithelial injury increased with PVR using an isolated heart-lung ischemia-reperfusion model, suggesting PVR is a reliable indirect indicator of lung injury. The fact that PVR increased after coro- nary artery occlusion-reperfusion in Group-C, and that $\mathrm{PaO}_{2}$ and $\mathrm{PaO}_{2} / \mathrm{FIO}_{2}$ after 120 min reperfusion were negatively correlated with this early rise in PVR further supports this finding (Figure 2). This suggests that changes in PVR could serve as a sensitive predictor for pulmonary function deterioration after coronary occlusion/reperfusion in this model. Acute postoperative pulmonary hypertension and elevated PVR may cause morbidity and mortality in patients undergoing cardiac surgery involving $\mathrm{CPB} .{ }^{22}$ Recently, Li et al. ${ }^{10}$ reported that two cycles of three minutes of aortic cross clamping and two minutes of reperfusion (cardiac ischemic preconditioning) before cardioplegic arrest improves lung function in patients undergoing valve replacement operations. In their observations, two cycles of brief cardiac ischemic preconditioning were associated with a reduced PVR index and mean pulmonary artery pressure, which was accompanied by improved cardiac index as well as enhanced $\mathrm{PaO}_{2}$ after reperfusion. Also, histological findings confirmed a reduced alveolar injury in the cardiac ischemic preconditioned group. ${ }^{10}$ However, the method of global ischemic cardiac preconditioning is not applicable when OPCAB surgery is performed, since no aortic cross-clamping is possible during beating heart surgery. Furthermore, this method carries the risk of neurological damage by embolism of atheromatous material in the aorta during the cross-clamping. Therefore preconditioning by a short occlusion of a peripheral region or organ as performed in our experiments might clinically be far more relevant.

We report that sheep, submitted to a clinically relevant model mimicking OPCAB surgery, show an increase in PVR and jeopardized lung gas exchange. RPC induced by short ischemia of a non-vital organ completely prevented the increase of PVR and preserved lung gas exchange following coronary artery occlusion and reperfusion in our model. The underlying mechanism of the observations described in this experiment and in that of $\mathrm{Li}$ et al. ${ }^{10}$ needs to be further elucidated. It is not clear whether the same underlying mechanism is responsible for both observations. It is tempting, although speculative, to attribute a role to the $\mathrm{K}_{\mathrm{ATP}}$ channel, since: 1 ) activation of this channel causes pulmonary vascular vasodilatation;23,24 and 2) the end effector of myocardial protection by ischemic preconditioning is at least in part the $\mathrm{K}_{\mathrm{ATP}}$ channel. ${ }^{25,26}$ Further studies are warranted to unravel the underlying mechanism.

One may argue that the improvement in pulmonary function seen in Group-RPC might be attributable to the improvement in cardiac function as 
evidenced by increased $\mathrm{CO}$ and systemic arterial pressure in our experiment. We cannot completely exclude this possibility but think that this is not likely the major mechanism for the improvement in pulmonary function after repeated coronary occlusion and reperfusion in our model. Significant differences in $\mathrm{CO}$ and systemic arterial pressure between the groups were not observed until after $120 \mathrm{~min}$ reperfusion, while $\mathrm{PaO}_{2} / \mathrm{FIO}_{2}$ was already significantly lower and $\mathrm{PaCO}_{2}$ significantly higher in Group-C than in Group-RPC after $90 \mathrm{~min}$ of reperfusion (Tables II and III). Furthermore, there was no correlation between CO or systemic arterial pressure and pulmonary function described by $\mathrm{PaO}_{2} / \mathrm{FIO}_{2}$ and $\mathrm{PaO}_{2}$.

A weakness of our study is the fact that no control group was included without RPC and without coronary occlusions. Addition of this group might have clearly demonstrated the effect of the consecutive episodes of myocardial ischemia and reperfusion in itself. We had chosen to start with a model that mimics clinical OPCAB surgery, and then to try to reduce the pulmonary functional deterioration in this model by RPC.

In conclusion, the present study shows that in this sheep model, brief periods of ischemia followed by reperfusion in a remote peripheral non-vital organ can prevent pulmonary dysfunction following myocardial ischemia and reperfusion. This study may have clinical implications in OPCAB surgery. It might be of particular importance to those patients who have preexisting high PVR and pulmonary hypertension.

\section{References}

1 Hachenberg T, Tenling A, Nystrom SO, Tyden H, Hedenstierna $G$. Ventilation-perfusion inequality in patients undergoing cardiac surgery. Anesthesiology 1994; 80: 509-19.

2 Dagenais F, Cartier R. Pulmonary hypertension during beating heart coronary surgery: intermittent inferior vena cava snaring. Ann Thorac Surg 1999; 68: 1094-5.

3 Tasdemir O, Vural KM, Karagoz H, Bayazit K. Coronary artery bypass grafting on the beating heart without the use of extracorporeal circulation: review of 2052 cases. J Thorac Cardiovasc Surg 1998; 116: 68-73.

4 Malkowski MJ, Kramer CM, Parvizi ST, et al. Transient ischemia does not limit subsequent ischemic regional dysfunction in humans: a transesophageal echocardiographic study during minimally invasive coronary artery bypass surgery. J Am Coll Cardiol 1998; 31: 1035-9.

5 Slutsky RA, Mattrey RF. Pulmonary edema formation after myocardial infarction and coronary reperfusion: intravascular and extravascular pulmonary fluid vol- umes. IV. Circ Shock 1984; 13: 183-91.

6 Güler M, Kirali K, Toker ME, et al. Different CABG methods in patients with chronic obstructive pulmonary disease. Ann Thorac Surg 2001; 71: 152-7.

7 Meharwal ZS, Mishra YK, Kobli V, Bapna R, Singh S, Trehan $N$. Off-pump multivessel coronary artery surgery in high-risk patients. Ann Thorac Surg 2002; 74: S1353-7.

8 Gho BC, Schoemaker RG, van den Doel MA, Duncker $D J$, Verdouw PD. Myocardial protection by brief ischemia in noncardiac tissue. Circulation 1996; 94: 2193-200.

9 Birnbaum $\Upsilon$, Hale $S L$, Kloner $R A$. Ischemia preconditioning at a distance. Reduction of myocardial infarct size by partial reduction of blood supply combined with rapid stimulation of the gastrocnemius muscle in the rabbit. Circulation 1997; 96: 1641-6.

$10 \mathrm{Li}$ G, Chen S, Lu E, Luo W. Cardiac ischemic preconditioning improves lung preservation in valve replacement operations. Ann Thorac Surg 2001; 71: 631-5.

11 Groeneveld AB, Raijmakers PG, Rauwerda JA, Hack $C E$. The inflammatory response to vascular surgeryassociated ischaemia and reperfusion in man: effect on postoperative pulmonary function. Eur J Vasc Endovasc Surg 1997; 14: 351-9.

12 Latson TW, Kickler TS, Baumgartner WA. Pulmonary hypertension and noncardiogenic pulmonary edema following cardiopulmonary bypass asociated with an antigranulocyte antibody. Anesthesiology 1986; 64: 106-11.

13 Boldt J, von Bormann B, Kling D, Scheld HH,

Hempelmann $G$. The influence of extracorporeal circulation on extravascular lung water in coronary surgery patients. Thorac Cardiovasc Surg 1986; 34: 110-5.

14 Neumann FJ, Ott I, Gawaz M, et al. Cardiac release of cytokines and inflammatory response in acute myocardial infarction. Circulation 1995; 92: 748-55.

15 Liebold A, Keyl C, Birnbaum DE. The heart produces but the lungs consume proinflammatory cytokins following cardiopulmonary bypass. Eur J Cardiothorac Surg 1999; 15: 340-5.

16 Slutsky RA, Peck WW, Higgins CB. Pulmonary edema formation with myocardial infarction and left atrial hypertension: intravascular and extravascular pulmonary fluid volumes. Circulation 1983; 68: 164-9.

17 Richeson JF, Paulshock C, Yu PN. Non-hydrostatic pulmonary edema after coronary artery ligation in dogs. Protective effect of indomethacin. Circ Res 1982; 50: 301-9.

18 Collins JC, Harris TR, McKeen CR, Brigham KL. Increased lung lymph transport without heart failure after coronary ligation in sheep. J Appl Physiol 1979; 47: 792-7.

19 Febrenbach H, Schepelmann D, Albes JM, et al. 
Pulmonary ischemia/reperfusion injury: a quantitative study of structure and function in isolated heart-lungs of the rat. Anat Rec 1999; 255: 84-9.

20 Stamler A, Wang H, Weintraub RM, Hariawala MD, Fink MP, Johnson RG. Low-dose dopexamine's effect on lung and gut function after CPB in a sheep model. J Surg Res 1998; 74: 165-72.

21 Friedman $M$, Wang SY, Sellke FW, Franklin A, Weintraub RM, Johnson RG. Pulmonary injury after total or partial cardiopulmonary bypass with thromboxane synthesis inhibition. Ann Thorac Surg 1995; 59: 598-603.

22 Hopkins RA, Bull C, Haworth SG, de Leval MR, Stark $J$. Pulmonary hypertensive crises following surgery for congenital heart defects in young children. Eur J Cardiothorac Surg 1991; 5: 628-34.

23 Hood JS, McMahon TJ, Kadowitz PJ. Pulmonary vasodilator responses to RP52891 are mediated by activation of a glibenclamide-sensitive $\mathrm{K}+_{\text {ATP }}$ channel. Eur J Pharmacol 1991; 202: 121-4.

24 Minkes RK, Kvamme P, Higuera TR, Nossaman BD, Kadowitz PJ. Analysis of pulmonary and systemic vascular responses to cromakalim, an activator of $\mathrm{K}+{ }_{\text {ATP }}$ channels. Am J Physiol 1991; 260: H957-66.

25 Grover GJ, Garlid KD. ATP-sensitive potassium channels: a review of their cardioprotective pharmacology. J Mol Cell Cardiol 2000; 32: 677-95.

26 Gross GJ, Auchampach JA. Blockade of ATP-sensitive potassium channels prevents myocardial preconditioning in dogs. Circ Res 1992; 70: 223-33. 